\title{
STRATEGI REKLAMASI LAHAN PASCA TAMBANG
}

\author{
Hirfan $^{1}$ \\ ${ }^{1}$ Dinas PU Luwu Timur \\ 1' hirfan.pulutim@yahoo.com
}

\begin{abstract}
Abstrak
Salah satu cara untuk mengatasi kendala untuk melakukan reklamasi tambang dengan merumuskan model reklamasi lahan pasca tambang yang efektif dan efisien. Alternatif penggunaan lahan bekas tambang yang umum dilakukan adalah untuk kawasan kehutanan, pertanian, dan lokasi wisata. Pilihan dari skema reklamasi ini tergantung terutama kepada iklim (termasuk iklim mikro), topografi lahan pasca tambang, keberadaan tanah pucuk, jarak ke pusat-pusat perkotaan dan status lahan. Sebagai contoh, beberapa alasan mengapa hutan dipilih untuk skema reklamasi bisa karena lereng yang terbentuk setelah proses regrading masih terlalu curam untuk kegiatan pertanian, produksi hasil kayu hutan lebih menguntungkan, tanaman hutan mungkin ditanam hanya untuk memenuhi aspek estetik saja, atau status lahan mengharuskan lahan bekas tambang ditanami kembali dengan tanaman kehutanan.
\end{abstract}

Kata kunci : Reklamasi Tambang, Pasca Tambang, Hutan.

\section{PENDAHULUAN}

Pembangunan berwawasan lingkungan menjadi suatu kebutuhan penting bagi setiap bangsa dan negara yang menginginkan kelestarian sumberdaya alam. Oleh sebab itu, sumberdaya alam perlu dijaga dan dipertahankan untuk kelangsungan hidup manusia kini, maupun untuk generasi yang akan datang. Manusia merupakan posisi kunci penyebab utama terjadinya kerusakan lingkungan (ekosistem). Dengan semakin bertambahnya jumlah populasi manusia, kebutuhan hidupnya pun meningkat, akibatnya terjadi peningkatan permintaan akan lahan seperti pertanian dan pertambangan. Sejalan dengan hal tersebut dan dengan semakin hebatnya kemampuan teknologi untuk memodifikasi alam, maka manusialah yang merupakan faktor yang paling penting dan dominan dalam merestorasi ekosistem rusak.

Salah satu konsekuensi dari pembangunan aktifitas adalah penambangan yang akan mengakibatkan adanya lahan bekas tambang. Lahan pasca tambang dapat dianalisis secara fisik, kimia dan hidrologis. Secara fisik, lahan telah mengalami kerusakan, kedalaman efektif tanah menjadi dangkal, terdapat berbagai lapisan penghambat pertumbuhan tanaman seperti pasir, kerikil, lapisan sisa-sisa tailing dan pada kondisi yang parah dapat pula terlihat lapisan cadas. Bentuk permukaan tanah biasanya secara topografis sangat ekstrem, yaitu antara permukaan tanah yang berkontur dengan nilai rendah dan berkontur dengan nilai tinggi pada jarak pendek bedanya sangat menonjol. Dengan kata lain terdapat perbedaan kemiringan tanah yang sangat mencolok pada jarak pendek. Secara kimia, lahan tidak dapat lagi memberikan dukungan positif terhadap penyediaan unsur hara untuk pertumbuhan tanaman.

Alternatif penggunaan lahan bekas tambang yang umum dilakukan adalah untuk kawasan kehutanan, pertanian, dan lokasi wisata. Pilihan dari skema reklamasi ini tergantung terutama kepada iklim (termasuk iklim mikro), topografi lahan pasca tambang, keberadaan tanah pucuk, jarak ke pusat-pusat perkotaan dan status lahan. Sebagai contoh, beberapa alasan mengapa hutan dipilih untuk skema reklamasi bisa karena lereng yang terbentuk setelah proses regrading masih terlalu curam untuk kegiatan pertanian, produksi hasil kayu hutan lebih menguntungkan, tanaman hutan 
mungkin ditanam hanya untuk memenuhi aspek estetik saja, atau status lahan mengharuskan lahan bekas tambang ditanami kembali dengan tanaman kehutanan.

Tambang Ramah Lingkungan (green mining) merupakan komitment baru yang dibuat dan dilaksanakan oleh perusahaan tambang karena perusahaan tambang sudah waktunya mempertimbangkan kelestarian lingkungan dalam setiap aktivitas penambangan. Hal ini untuk mendorong keinginan perusahaaan mewujudkan perusahaan sebagai perusahaan Green Mining, yaitu perusahaan pertambangan hijau yang tidak merusak tetapi justru membantu mewujudkan kelestarian fungsi hutan di Indonesia. Sehingga perusahaan tersebut juga layak mendapat predikat "green company" karena komitmennya dalam melestarikan dan memelihara lingkungan hidup. Upaya tersebut dilakukan dengan melakukan perbaikan pada teknik reklamasi bekas tambang yang selesai ekploitasinya. Meskipun komitmen untuk mewujudkan Green Mining telah dilaksanakan perusahaan pertambangan, namun banyak pula perusahaan yang baru mulai melakukannya dengan mempelajari pelaksanaan penanaman yang baik di Departemen Kehutanan.

Ada beberapa hal penting yang perlu mendapatkan perhatian perusahaan pertambangan agar dapat menjadi perusahaan yang ramah lingkungan. Tahapan untuk menjadi perusahaan tambang "Green Mining" adalah: (1) perusahaan pertambangan harus mengelola sumber daya alam dengan baik dan memelihara daya dukungnya agar bermanfaat bagi peningkatan kesejahteraan rakyat dari generasi ke generasi; (2) perusahaan pertambangan perlu meningkatkan pemanfaatan potensi sumber daya alam dan lingkungan hidup dengan melakukan konservasi, rehabilitasi dan penghematan penggunaan, dengan menerapkan teknologi ramah lingkungan, (3) perusahaan pertambangan perlu mendayagunakan sumber daya alam untuk sebesarbesarnya kemakmuran rakyat dengan memperhatikan kelestarian fungsi lingkungan dan keseimbangan lingkungan hidup, pembangunan yang berkelanjutan, kepentingan ekonomi dan budaya masyarakat lokal, serta penataan ruang, yang pengusahaannya diatur dengan undang-undang. Perusahaan pertambangan perlu menerapkan indikator-indikator yang memungkinkan pelestarian kemampuan keterbaharuan dalam pengelolaan sumber daya alam yang dapat diperbaharui untuk mencegah kerusakan yang tidak dapat pulih.

Reklamasi lahan bekas tambang bertujaun untuk mengembalikan manfat hutan ssesuai dengan fungsinya. Pemahaman kondisi ekologi sangat penting dalam reklamasi bekas tambang, karena reklamasi bekas tambang diharapkan menghasilkan kondisi ekologis tapak sama dengan kondisi hutan alam sebelumnya. Kunci keberhasilan reklanasi lahan bekas tambang sangat bergantung pada kondisi ekologi daerah reklamasi. Ilmu ekologi dapat dengan baik menjelaskan karakteristik tapak bekas tambang dan hidupan yang ada di dalamnya termasuk jenis vegetasi yang tumbuh. Dengan menguasai ilmu tersebut, dapat digunakan untuk menentukan dan mencari jenis-jenis lokal pioner di dalam daerah eks tambang. Kemampuan pengetahuan ekologi dapat digunakan untuk mengamati sekitar terutama terkait nanti ketika mencari benih atau bibit lokal yang tidak tersedia di lokasi. Kemiripan sifatsifat ekologi area tambang dapat dijadikan dasar menentukan bahwa suatu jenis tertentu dapat ditanaman pada kondisi ekologis yang mirip meskipun secara geografis berjauhan.

Reklamasi bekas tambang merupakan tantangan besar karena tingkat kesulitan teknologi serta tingkat kerusakan area bekas tambang yang umumnya cukup tinggi. Sebagai contoh bekas tambang yang meninggalkan kondisi lahan 
dengan drainase yang asam. Drainase tambang asam (Acid Mine Drinage) adalah air yang kaya logam terbentuk dari reaksi kimia antara air dan batuan yang mengandung mineral sulfur. Keasaman drainase tambang batu bara terutama disebabkan oleh oksidasi pirit mineral (FeS2), yang ditemukan dalam batubara, overburden batu bara, dan tumpukan limbah tambang. Laju oksidasi pirit ini tergantung pada luas permukaan reaktif dari pirit, konsentrasi oksigen dan $\mathrm{pH}$ air, bentuk pirit, dan keberadaan bakteri Fe-oksidasi (Thiobacillus Ferroxidans).

Secara teknis penggunaan direct seedling sangat menguntungkan karena bibit sudah memiliki daya adaptasi dengan lingkungan (tanah) lokasi penanaman. Terutama menyangkut perakaran, karena perakaran merupakan saran untuk mendapat nutrisi bagi tanaman. Dengan menanam "direct seedling" berarti menanam bibit dengan akar yang sudah memiliki daya adaptabilitas terhadap tempat tumbuhnya (bekas tambang). Penanaman benih di lahan bekas tambang agak sulit karena kondisi tanah yang sudah tidak sesuai dengan kondisi dimana biji dapat berkecambah secara alami, karena kerusakan fisik tanah dan pencemaran zat kimia. Dengan menggunakan direct seedling akan mengatasi masalah kelangkaan benih yaitu misalnya dengan teknik kultur jaringan dan stek pucuk bisa mendapatkan bibit dalam jumlah besar. Selain itu menanam biji juga resiko tidak tumbuh besar dibandingkan dengan bibit. Apalagi biji jenis yang akan ditanam ukurannya sangat kecil, sehingga sulit untuk menanamnya langsung.

Pengetahuan yang diperlukan untuk mendukung teknik direct seedling adalah kemampuan bagaimana dapat mengenali bibit yang baik dan cara memobilisasi bibit ke area reklamasi. Misalnya kemampuan membuat puteran untuk memindahkan bibit pada berbagai ukuran dan kelas umurnya. Yang harus diperhatikan pada saat memindahkan bibit ke lokasi tanam adalah bagaimana memperlakukan seedling sehingga tidak merusak akarnya. Reklamasi bekas tambang dimaksudkan untuk mendapatkan kondisi hutan mendekati seperti sebelumnya. Oleh karenanya sangat ditekankan untuk menanam jenis-jenis lokal setempat. Dalam PerMenHut RI No 6 Tahun 2009 telah diatur bahwa komposisi jenis lokal adalah lebih besar atau sama dengan 40 persen terhadap jumlah pohon.

Adapun jenis-jenis lokal menurut PerMenHut tersebut adalah jenis-jenis tanaman asli atau eksotik yang disukai masyarakat dan mempunyai keunggula tertentu seperti produksi kayu, buah dan getah; dan produknya mempunyai nilai ekonomi yang tinggi, misalnya jenis jati (Techtona grandis), Rasamala (Altingia excelsa), Mahoni (Switenia sp.), Cempaka, dan jenis spesies multi purpose lainnya. Contoh pohon lokal lain yang dapat ditanam sebagai berikut: (1) toleran (bisa di bawah naungan), terdiri dari meranti (Shore sp.) berguna memproduksi hasil hutan kayu (wood working), belangeran (Shore belangeran) berguna memproduksi hasil hutan kayu (wood working) dan rengas (Mellanorhoea walichii) berguna memproduksi hasil hutan kayu (wood working); (2) in toleran (tempat terbuka), terdiri dari: aakasia (Akasia mangium) berguna sebagai bahan baku kertas dan pulp, jelutung (Dyera lowii) yang menghasilkan getah jelutung dan, pulai (Alstonia scholaris) berguna memproduksi hasil hutan kayu (wood working).

Kegiatan pertambangan mempunyai karakteristik lahan yang khas dibandingkan dengan karakteristik kegiatan lainnya, terutama menyangkut sifat, jenis dan lokasinya. Kegiatan pertambangan melibatkan eksploitasi sumberdaya alam yang tidak dapat diperbaharui dan sering ditemukan pada lokasi-lokasi yang terpencil. Selain itu pembangunan membutuhkan investasi yang besar terutama untuk 
membangun fasilitas infiastruktur. Karakeristik yang penting lainnya bahwa jumlah cadangan sumberdaya tidak dapat diketahui dengan pasti menyebabkan industri pertambangan dioperasikan pada tingkat resiko yang tinggi baik dari segi aspek fisik, perdagangan, sosial ekonomi maupun aspek politik.

Berbagai aktivitas dalam kegiatan penambangan menyebabkan rusaknya struktur, tekstur, porositas dan bulk density sebagai karakter fisik tanah yang penting bagi perturnbuhan tanaman. Kondisi tanah yang kompak karena pemadatan menyebabkan buruknya sistem tata air (water infiltration and percolation) dan peredaran udara (aerasi) yang secara langsung dapat membawa dampak negatif terhadap fungsi dan perkembangan akar. Akar tidak dapat berkembang dengan sempurna dan fungsinya sebagai alat absorpsi unsur hara akan terganggu, akibatnya tanaman tidak dapat berkembang dengan normal.

Rusaknya struktur dan tekstur juga menyebabkan tanah tidak mampu untuk menyimpan dan meresap air pada musim hujan, sehingga aliran air permukaan (surface run off) menjadi tinggi. Sebaliknya tanah menjadi padat dan keras pada musim kering sehingga sangat berat untuk diolah yang secara tidak langsung berdarnpak pada kebutuhan tenaga kerja.

\section{METODOLOGI PENELITIAN}

Perintisan (Pioneering) adalah kegiatan persiapan yang mencakup pembuatan sarana jalan angkut dan penanganan sarana air drainase (saluran). Dalam pembuatan jalan, lebar dan kemiringan jalan harus sesuai dengan yang direncanakan sehinggga hambatan-hambatan dalam pengangkutan bijih (ore) mineral dapat diatasi dan tingkat keamanan pengguna jalan lebih terjamin. Untuk pembuatan jalan dapat dilakukan dengan menggunakan bulldozer. Permasalahan air tambang mencakup pembuatan saluran, sumuran dan kolam penggendapan. Dimensi saluran, sumuran dan kolam penggendapan harus disesuaikan dengan debit air yang ada, sehingga air tambang tidak langsung mengalir ke air bebas yang dapat menimbulkan masalah lingkungan.

Pembabatan (Clearing) adalah kegiatan atau pekerjaan pembersihan daerah yang akan ditambang dari semak-semak, pohon-pohon kecil dan tanah maupun bongkahan-bongkahan yang menghalangi pekerjaan selajutnya. Peralatan yang sering digunakan untuk kegiatan pembersihan tanah tarnbang adalah tenaga manusia seperti gergaji, bulldozer, truk cungkil dan penggaruk (ripper).

Pengupasan tanah penutup (Stripping) yang dilakukan pada lapisan tanah penutup biasanya dilakukan bersama-sama dengan clearing dan menggunakan bulldozer. Pekerjaan dimulai dari tempat yang lebih tinggi (puncak bukit) dan tanah penutup didorong ke bawah kearah tempat yang lebih rendah sehingga alat dapat bekerja dengan bantuan gaya gravitasi.

Pembuatan bench kelompok blok dan dimensi dari pada endapan akan turut mempengaruhi. Bagian lereng bukit yang akan dipotong pada waktu pembuatan bench tersebut jika mempunyai kadar yang cukup untuk di tambang maka akan diambil dan dianggap sebagai bijih produksi, akan tetapi jika kadarnya rendah maka bagian tersebut didorong kesamping.Untuk menentukan lokasi dan jumlah bench yang akan dibuat yaitu berdasarkan pada tebal dan penyebaran dari pada endapan bijih dan diusahakan agar alat-alat mekanis yang digunakan dapat bergerak dengan baik, serta ketinggian bench maksimal 4 meter. 


\section{HASIL DAN PEMBAHASAN}

Reklamasi lahan bekas tambang selain merupakan upaya untuk memperbaiki kondisi lingkungan pasca tambang, agar menghasilkan lingkungan ekosistem yang baik dan juga diupayakan menjadi lebih baik dibandingkan rona awalnya, dilakukan dengan mempertimbangkan potensi bahan galian yang masih tertinggal. Prinsip lingkungan hidup yang wajib dipenuhi dalam melaksanakan reklamasi dan pasca tambang adalah: (1) perlindungan terhadap kualitas air permukaan, air tanah, air laut, tanah dan udara; (2) perlindungan keanekaragaman hayati; (3) penjaminan stabilitas dan keamanan timbunan batuan penutup, kolam tailing, lahan bekas tambang dan struktur buatan lainnya; (4) pemanfaatan lahan bekas tambang; (5) memperhatikan nilai-nilai sosial dan budaya setempat; (6) perlindungan terhadap kuantitas air tanah

Kegiatan reklamasi merupakan akhir dari kegiatan pertambangan yang diharapkan dapat mengembalikan lahan kepada keadaan semula, bahkan jika memungkinkan dapat lebih baik dari kondisi sebelum penambangan. Kegiatan reklamasi meliputi pemulihan lahan bekas tambang untuk memperbaiki lahan yang terganggu ekologinya dan mempersiapkan lahan bekas tambang yang sudah diperbaiki ekologinya untuk pemanfaatan selanjutnya. Sasaran akhir dari reklamasi adalah untuk memperbaiki lahan bekas tambang agar kondisinya aman, stabil dan tidak mudah tererosi sehingga dapat dimanfaatkan kembali.

Secara teknis usaha reklamasi lahan tambang terdiri dari recontouring/ regrading/resloping lubang bekas tambang dan pembuatan saluran-saluran drainase untuk memperoleh bentuk wilayah dengan kemiringan stabil, top soil spreading agar memenuhi syarat sebagai media pertumbuhan tanaman, untuk memperbaiki tanah sebagai media tanam, revegetasi dengan tanaman cepat tumbuh, tanaman asli lokal dan tanaman kehutanan introduksi. Perlu juga direncanakan pengembangan tanaman pangan, tanaman perkebunan dan atau tanaman hutan industri, jika perencanaan penggunaan lahan memungkinkan untuk itu. Secara umum, garis besar tahapan reklamasi yaitu:

1) Konservasi top soil, Beberapa hal yang harus diperhatikan, adalah: (a) menghindari tercampurnya subsoil yang mengandung unsur atau senyawa beracun, seperti pirit, dengan tanah pucuk, dengan cara mengenali sifat-sifat lapisan tanah sebelum penggalian dilakukan, (b) menggali tanah pucuk sampai lapisan yang memenuhi persyaratan untuk tumbuh tanaman, (c) menempatkan galian tanah pucuk pada areal yang aman dari erosi dan penimbunan bahan galian lainnya, (d) menanam legum yang cepat tumbuh pada tumpukan tanah pucuk untuk mencegah erosi dan menjaga kesuburan tanah.

2) Penataan lahan, Penataan lahan dilakukan untuk memperbaiki kondisi bentang alam, antara lain dengan cara: (a) menutup lubang galian (kolong) dengan menggunakan limbah tailing (overburden). Lubang kolong yang sangat dalam dibiarkan terbuka, untuk penampung air; (b) membuat saluran drainase untuk mengendalikan kelebihan air, (c) menata lahan agar revegetasi lebih mudah dan erosi terkendali, diantaranya dilakukan dengan cara meratakan permukaan tanah, jika tanah sangat bergelombang penataan lahan dilakukan bersamaan dengan penerapan suatu teknik konservasi, misalnya dengan pembuatan teras, (d) menempatkan tanah pucuk agar dapat digunakan secara lebih efisien. Karena umumnya jumlah tanah pucuk terbatas, maka tanah pucuk diletakan pada areal atau jalur tanaman. Tanah pucuk dapat pula diletakkan pada lubang tanam. 
3) Pengelolaan sedimen dan pengendalian erosi, Pengelolaan sedimen dilakukan dengan membuat bangunan penangkap sedimen, seperti rorak, dan di dekat outlet dibuat bangunan penangkap yang relatif besar.

4) Penanaman cover crop (tanaman penutup) merupakan usaha untuk memulihkan kualitas tanah dan mengendalikan erosi. Oleh karena itu keberhasilan penanaman penutup tanah sangat menentukan keberhasilan reklamasi lahan pasca penambangan. Karakteristik cover crop yang dibutuhkan, sebagai berikut: mudah ditanam, cepat tumbuh dan rapat, bersimbiosis dengan bakteri atau fungi yang menguntungkan (rhizobium, frankia, azospirilum, dan mikoriza), menghasilkan biomassa yang melimpah dan mudah terdekomposisi, tidak berkompetisi dengan tanaman pokok dan tidak meliliki.

5) Penanaman tanaman pionir, untuk mengurangi kerentanan terhadap serangan hama dan penyakit, serta untuk lebih banyak menarik binatang penyebar benih, khususnya burung, lebih baik jika digunakan lebih dari satu jenis tanaman pionir/multikultur. Beberapa jenis tanaman pionir adalah : sengon buto (Enterrolobium cylocarpum), Sengon (Paraserianthes falcataria), johar (Casia siamea), Cemara (Casuarina sp.), dan Eukaliptus pelita. Dalam waktu dua tahun kerapatan tajuk yang dibentuk tanaman-tanaman tersebut mampu mencapai 50$60 \%$ sehingga kondusif untuk melakukan restorasi jenis-jenis lokal, yang umumnya bersifat semitoleran. Tanaman pioner ditanam dengan sistem pot pada lubang berukuran lebar x panjang x dalam sekitar 60 × 60 x $60 \mathrm{~cm}$, yang diisi dengan tanah pucuk dan pupuk organik. Dibeberapa lokasi, tanaman pioneer ditanam langsung setelah penataan lahan, padahal tingkat keberhasilannya relatif rendah.

6) Penanggulangan Logam Berat, pada areal yang mengandung logam berat dengan kadar di atas ambang batas diperlukan perlakuan tertentu untuk mengurangi kadar logam berat tersebut. Vegetasi penutup tanah yang digunakan untuk memantapkan timbunan buangan tambang dan membangun kandungan bahan organik, bermanfaat pula untuk mengurangi kadungan logam berat dengan menyerapnya ke dalam jaringan. Beberapa laporan juga menunjukkan bahwa bahan organik berkorelasi negatif dengan kelarutan logam berat di dalam tanah, karena keberadaan bahan organik tanah meningkatkan kapasitas tukar kation (KTK) tanah. Hasil penelitian menunjukkan pemberian bahan organik dikombinasikan dengan pencucian dapat menurunkan kandungan logam mercuri (Hg) dalam tanah sampai $84 \%$. Pada areal dengan kandungan logam berat tinggi sebaiknya jangan dulu dilakukan penanaman komoditas yang dikonsumsi. Perlu dipilih jenis tanaman yang toleran terhadap logam berat, misalnya di Ameria Serikat ditemukan jenis tanaman pohon hutan, diantaranya Betula spp. dan Salix spp. yang dapat bertahan hidup di areal bekas tambang yang mengandung $\mathrm{Pb}$ sampai $30.000 \mathrm{mg} / \mathrm{kg}$ dan Zn sampai $100.000 \mathrm{mg} / \mathrm{kg}$. Kemampuan ini ternyata dibangkitkan oleh asosiasi pohon dengan mikoriza. Perlu diidentifikasi tanamantanaman lain yang toleran terhadap logam berat yang dapat tumbuh baik di wilayah tropis seperti Indonesia. Selain dalam tanah penanggulangan pencemaran logam berat dalam air juga harus dilakukan, tanaman eceng gondok dapat digunakan untuk membersihkan badan air dari logam berat. Penanganan logam berat dengan mikroorganisme atau mikrobia (dalam istilah biologi disebut dengan bioakumulsi, bioremediasi, atau bioremoval), menjadi alternatif yang 
dapat dilakukan untuk mengurangi keracuan elemen logam berat di lingkungan perairan.

\section{PENUTUP}

Pada umumnya reklamasi yang dilakukan oleh para perusahaan pertambangan saat ini ditemukan beberapa kendala diantaranya, memerlukan biaya yang sangat besar dan teknologi modern, sehingga yang sanggup melakukan hal ini hanya perusahaan besar saja dan luasan yang reklamasi hanya sebagian kecil saja, apakah sebanding antara lahan yang rusak dengan yang direklamasi, dan nampaknya kegiatan reklamasi dilakukan tidak serius, terkesan tanam buang karena terkendala oleh iklim. Sementara itu ada alternatif yang ditawarkan dalam rangka reklamasi lahan bekas tambang dengan konsep tidak memerlukan biaya yang besar dan jangkauan reklamasi lebih luas, mudah dan murah ; yakni dengan konsep kembali kealam atau reklamasi lahan bekas tambang secara hayati.

\section{DAFTAR PUSTAKA}

Assosiasi Pertambangan Indonesia. "Green Mining” Perlu Diperhatikan. http://www.ima-api.com/index.php [akses : 5 Juli 2015].

Adnan Awad (UNDP) and KLH, "Overview of Risk Factors Associated with Disposal of Sidoarjo Mud at Sea”, Sept 8, 2006.

Atlas Kayu Indonesia. 2005. Badan Litbang kehutanan. Departemen Kehutanan. Bogor. Coal Mining and The Environment. Acid Mining Drinage (AMD). (http://energy.er.usgs.gov/health_environment/acid_mine_drainage/) [akses : 5 Juli 2010].

Barrow, C.J. 2011. Degradation of Tropical Rain Forest, Tropical/Sub Tropical Seasonally Organisme ang Tropical/Sub Tropical Upland Forests, Woodlands and Saruglands. Land Degradation Development and Breakdown of Terrestrial Environments. Cambridge-UK.

Bradshaw, A.D. 1983. The Restoration of Mined Land. Conservation in Perspective Edited by A. Warren and F.B. Goldsmith, John Willey and Sons Ltd.

Departemen Kehutanan Republik Indonesia. 2009. Peraturan Menteri Kehutanan No. 60 Tahun 2009. Mineral Information Institute. Reclamatin Succes : Larson Mining Enterprises. (http://www.worldcoal.org/coal-the-environment/coalmining-the-environment) [akses : 5 Juli 2010].

Elliott, S., D. Blakesley., J.F. Maxwell., S. Doust \& S. Suwannaratana. 2006. Bagaimana Menanam Hutan: Prinsip-prinsip dan Praktek Umum Merestorasi Hutan Tropis. The forest Restoration Research Unit (CMU). The United Kingdom's Darwin Initiative.

Grinwald, C., Iverson L.R and Szafoni, D.B. Abandoned Mines in Illinois and North Dakota Rehabilitation Damage Ecosystem Vol I edited by John Cairas Jr. CRC Press Inc. Bucaraton, Flourida.

Jordan, C.F. 1985. Canges in Nutrient Cycles due to Disturbance. Nutrient Cycling in Tropical Forest Ecosystem: Principles and Their Application in Management and Conservation. John Willey and Sons. New York.

Jordan, W.R., M.E. Gopin., and J.D. Aber. 1993. Disturbed Ecosystems as Opportunities for Research in Restoration Ecology. A synthetic Approach to Ecological Research, University Press. Cambridge. UK. 
Kartasapoetra, A.G, dkk. 2005. Teknologi Konservasi Tanah \& Air- Edisi Kelima. PT Rineka Cipta, Jakarta.

Kuiper, J. 1983.Effects of mercury on enclosed plankton communities in the Rosfjord during POSER http://www.int-es.com/articles/meps/14/m014p093.pdf Diakses tanggal 21 Juli 2015.

Lugo, A.E. 1997. The Apparent Paradox of Reestablishing Species Richness on Degradedlands with Tree Monocultures. Forest Ecology ang Management.(99)p: 9-19.

Manasveta, P. 1975. Aquatic Environmental Mercury Contamination http://www.scienceasia.org/1975.01.n3/v01_167_177.pdf Diakses tanggal 23 Juli 2015.

Nugroho, A.W. \& I. Yassir. 2012. Penanaman Jenis Lokal di Lahan Bekas Tambang Batubara, Kalimantan Timur. Rencana Penelitian Tim Peneliti. Balai Penelitian Teknologi Konservasi Sumber Daya Alam. Samboja.

Ripley, E.A., Redmann, R.E. and Croeder, A.A. 1996. Prevention, Reclamation and Rehabilitation. Environmental Effects Minning St. Lucie Press. Florida.

UN Disaster Assessment and Coordination, "Environmental Assessment: Hot Mud Flow, East Java-Indonesia”, July 2006.

Wibisono, I.T.C. Tanpa Tahun. Panduan Silvikultur Untuk Rehabilitasi Lahan Gambut Bekas Kebakaran dan Terlantar Silviculture Manual For Rehabilitation Ex-Burnt And Abandoned Peatlands. Ccfpi Consultant Wetlands International -Indonesia Programme.

Widuri, S. A, \& I. Yassir. 2012. Perbaikan Kesuburan Tanah Bekas Tambang Batubara dengan Asam Humat dan Kompos. Rencana Penelitian Tim Peneliti. Balai Penelitian Teknologi Konservasi Sumber Daya Alam. Samboja.

Yassir, I. \& R. M. Omon. 2009. Pemilihan jenis-jenis pohon potensial untuk mendukung kegiatan restorasi lahan tambang melalui pendekatan ekologis. Prosiding Workshop IPTEK Penyelamatan Hutan Melalui Rehabilitasi Lahan Pasca Tambang Batubara, Banjarmasin, 21 Oktober 2009. Balai Besar Penelitian Dipterokarpa. Samarinda.

Yassir, I., \& Arbainsyah. 2011. Diversity of Plant Communities upon Secondary Succession in Imperata Grasslands of East Kalimantan, Indonesia. Disampaikan dalam International Meeting Strengthening Forest Science and Technology for Better Forestry Development.

Yassir, I., Widuri, S.A., \& Nugroho, A.W. 2012. Identifikasi dan Uji coba Jenis Lokal untuk Mendukung Kegiatan Rehabilitasi Lahan Pasca Tambang. Disampaikan dalam Seminar Hasil-Hasil Penelitian BPTKSDA. Pusat Penelitian dan Pengembangan Konservasi dan Rehabilitasi. 